\title{
Moral Complexities of Student Question-Asking in Classroom Practice
}

Stephen C. Yanchar

Brigham Young University, Utah, USA

stephen_yanchar@byu.edu

Susan P. Gong

Brigham Young University, Utah, USA

spgong@gmail.com

\section{Abstract}

Prior research on student question-asking has primarily been conducted from a cognitive, epistemological standpoint. In contrast, we present a hermeneutic-phenomenological investigation that emphasizes the moral-practical context in which question-asking functions as a situated way of being in the midst of practice. More particularly, we present a hermeneutic study of student question-asking in a graduate seminar on design theory (i.e., a seminar focused on theory and philosophy of design, emphasizing the work of design scholars such as Simon, Cross, Krippendorff, and Lawson). The study offers a unique moral-practical perspective on this commonly studied phenomenon. Our analysis yielded four themes regarding the moral-practical intricacies of question-asking in this setting, with a particular focus on time-related constraints on participation, various types of background understanding, and value-laden expectations that participants encountered in this complex ecology of practice.

Keywords: student question-asking, graduate school, practices, hermeneutics, moral realism

\section{Introduction}

Student question-asking has traditionally been studied in contexts of learning, cognition, and various domains of education. By and large, scholarship in these areas has been informed by enlightenment assumptions regarding knowing, mind, and world—assumptions that frame question-asking as an almost exclusive process of knowledge gathering in the form of filling mental space with needed content (information, sensory experience, representations, etc.). Within this tradition, questioning is treated primarily as an epistemological, rather than ontological or axiological, phenomenon. In contrast, the hermeneutic study we present here situates question-asking in an intrinsically moral-practical space, allowing it to be revealed in a unique and, we suggest, insightful way. To set the stage for this study we offer a brief review of literature on question-asking, followed by a description of the hermeneutic moral-realist interpretive frame upon which this investigation was based. 


\section{Prior Research on Question-Asking}

Many studies of student question-asking focus on cognitive mechanisms such as representational structures theorized to exist in the mind, along with the computational procedures that operate on those structures (Chin \& Osborne, 2008; Otero \& Graesser, 2001; Tsui, 1992). Related research has focused on information search strategies (Mosher \& Hornsby, 1968), sequencing of information (Robertson \& Swartz, 1988), use of schemata and scripts (Flammer et al., 1981), and domain knowledge and heuristics (Schraagen, 1993; Siegler, 1977). Research on responses to questions has studied questions as the cause of some effect, usually involving tasks such as gathering information (Dreher \& Brown, 1993), constructing answers (Nelson-LeGall \& Glor-Scheib, 1985; Newman, 1991), and processing answers (Van der Meij, 1990). Research in this area has also investigated the relationship between questions, understanding, and learning styles (Pedrosa de Jesus et al., 2004).

Though still focused on knowledge-gathering per se, other forms of inquiry have examined the grammatical and semantic structures of questions. This general approach has focused on the syntax and semantics of questions in order to create a metalanguage or system of symbols that allow questions to be abstracted, categorized, evaluated, and connected to answers (Belnap \& Steel, 1977). Such research has, in this way, often focused on the underlying logical structure of questions (Prior \& Prior, 1955). Based on such inquiry, researchers have contended that the question-answer relation fundamentally underlies all reasoning, both valid and invalid (Koralus \& Mascarenhas, 2013).

Other investigations have studied questions as an impetus to learning, largely focusing on strategies to elicit questions that allow students to acquire content (Chin \& Osborne, 2008; Harper, Etkina, \& Lin, 2003, King, 1994; Wong, 1985). These studies are based on the assumption that students can be trained to ask questions that lead to increased learning and literacy (Davey \& McBride, 1986; King, 1989; Singer \& Donlan, 1982). Strategies for improving the effectiveness of questions include practical advice in addition to more theoretically derived alternatives focused on text-based comprehension, science-based strategies, problem-based learning, and socially situated initiatives (see Gong, 2018 for a review). As these trends in the literature suggest, student questions are typically studied in cognitive and logiccentered terms; they are commonly conceptualized as part of a dualist, representationalist epistemological apparatus of some form. Moreover, the studies that make up these trends are quantitative in nature, typically emphasizing statistical relations among variables.

By contrast, a few studies have investigated student question-asking by virtue of qualitative research approaches. Some (Van Zee, 2000; Van Zee et al., 2001) have utilized ethnography of communication to explore the experiences of teachers as they strived to elicit student questioning and document the types of questions that students generated based on these elicitations, while another (Volkman, 2004) used van Manen's (1990) hermeneutic phenomenology to explore a graduate student's experience as she learned how to respond to undergraduate student questions in a physics course. Whereas these qualitative studies have primarily emphasized the instructor's perspective and experience, another (Rop, 2003) used ethnography to explore the experiences of several high school students who commonly asked questions in their classes. In this latter study, the author offered insight into the challenges that sometimes accompany student question-asking in the classroom-for example, feeling various kinds of social pressure to ask fewer questions by teachers and other students. 
Finally, in a previously published qualitative report (Gong \& Yanchar, 2019), we explored student question-asking using the same hermeneutic moral realist interpretive frame that we describe below. Our findings in the previous report, based on this interpretive frame, pointed to the issue of how student question-asking functioned as a way of contributing - or not - to the common good of the class we investigated. Based on our analysis, student questionasking sometimes facilitated learning, sometimes occluded it, and, at times, created challenging classroom dynamics, including tensions among class members.

While these qualitative reports were revealing in some ways, they constitute a small proportion of the student question-asking literature in education and are significantly outstripped in frequency by quantitative investigations of cognitive and logic centric phenomena. It should come as little surprise that this would be the case, given the widespread acceptance of various representationalist-cognitive models over the past sixty years. However, in light of the many critiques of multiple generations of cognitive science (e.g., Dreyfus, 1992; Spackman \& Yanchar, 2014; Suchman, 1987; Wheeler, 2005) and concomitant experimental research paradigms (Yuille, 1986), efforts to provide more experiential, qualitative studies conducted from a primarily non-cognitive, non-epistemological standpoint seem warranted. What aspects of student question-asking in the classroom, it might be asked, can be revealed by inquiries that continue to explore this phenomenon from novel, experiential perspectives?

\section{A Hermeneutic Moral Realist Perspective on Question-Asking}

As a further exploration of this possibility, we report here an investigation of questionasking as a lived, in-the-world practice, rooted in the hermeneutic-phenomenological writings of Heidegger (1962, 1971), Gadamer (1989), Taylor (1985, 1989), and Dreyfus (1992, 2014). Whereas traditional cognitive accounts are informed by assumptions such as (but not limited to) dualism (i.e., a mind-body split), representationalism (e.g., mental schemas, scripts, networks), and mechanism (i.e., determinant structures and operations that govern information processing), the hermeneutic basis of our inquiry was informed by assumptions such as participation-in-theworld as a unitary phenomenon and understanding and interpretation as projecting and pressing into possibilities. These assumptions provide the basis for a non-dualist, non-representationalist account of human agency (for more on hermeneutic accounts of agency, see Guignon, 2002; Martin et al., 2003; Yanchar, 2011).

From this hermeneutic perspective, agents-in-the-world learn through a dynamic and continuous interplay of background understanding, concernful participation, interruption, exploration, and tacitization that leads to a fully-embodied and situated (but unfinalizable) kind of familiarity within a particular practice (Dreyfus, 2014; Yanchar et al., 2013). Moreover, from this perspective, questions are viewed ontologically - they flow out of one's background familiarity, concernful participation, ways of learning, and stance-taking on a given subject matter or phenomenon. As Taylor (1989) stated:

We take as basic that the human agent exists in a space of questions. And these are the questions to which our framework-definitions are answers, providing the horizon within which we know where we stand, and what meanings things have for us. (p. 29)

Questioning in this hermeneutic sense is more than merely academic. It lies at the core of what it means to be open to experience (Bingham, 2005; Gadamer, 1989; Taylor, 1989). One's question-asking is, in this sense, a way of being in the world; an expression of one's agency and 
a way in which the world is disclosed. In this regard, hermeneutics moves theorizing about question-asking away from the detached Cartesian model of scientific objectivity toward immersion in a world of "everyday concerns, practical involvements...inherited customs and traditions, social relations and language uses" (Hatab, 2000, p. 11). Exploring question-asking from this perspective is not a search for objectively specified generalizations that demonstrate initial states and outcomes; rather, it suggests situated, fully embodied integration and reintegration in a lived world of practical significance. Thus, from this perspective, a crucial methodological commitment involves the study of question-asking as a form of social practice in the lived spaces of everyday comportment rather than an isolated phenomenon in abstract mental or experimental space.

With regard to student question-asking in formal educational settings, hermeneutics implies a methodological commitment to studying learners' lived experiences as they navigate the relational complexities of actual practice in a variety of academic contexts. As we will clarify below, however, a study of question-asking in lived spaces of practical involvement also implies exploration of the value-laden, morally-constituted nature of academic practice itself (Brinkmann, 2004, 2011; Stigliano, 1990; Taylor, 1989; Yanchar \& Slife, 2017). As Brinkmann (2004) argued, "We cannot describe the human world adequately without at the same time describing values, goods, and reasons for action" (p. 57). Thus, studying phenomena in light of real, in-the-world moral goods and values allows researchers to take fuller account of the manytiered, complex and potentially conflicting layers of meaningful participation in practice.

Bringing tensions among various (often tacit) moral demands to the foreground, for instance, can make visible the often-tacit moral ecology of a given practice and offer an opportunity to explore the goods and values endemic to it (Yanchar \& Slife, 2017). In this sense, real-world banalities as well as challenges, complexities, accidents, excitements and surprises create important threads for inquiry into the moral space of practice. Bringing these threads together is a central task of interpretive researchers who seek to describe and understand phenomena within what Brinkmann (2004, p. 59) called a "moral topography" - a view of how the organization of values and goods are embedded in social practices.

Having assumed this hermeneutic moral realist perspective, we conducted an investigation of student question-asking in a formal setting, namely, a graduate seminar on design theory in education. Our intent was to provide unique insight into this ordinary aspect of academic practice - insight that may not only inform understandings of question-asking in this kind of highly-interactive educational context but also the broader meaning of question-asking as a ubiquitous human phenomenon. Given this background framing-which has not been employed in other studies of this topic, including qualitative studies - our general research questions were as follows: How does student question-asking fit into the moral configuration of goods and values in this graduate class? And what is revealed about student question-asking when studied from this perspective?

\section{Study Overview}

We used the interpretive frame described below to provide an analysis of student question-asking in a graduate class on design thinking. Methodologically speaking, our investigative strategy was similar to other hermeneutic-phenomenological approaches that emphasize the explication of everyday activity and its meaning (e.g., Addison, 1992; Packer, 1985; van Manen, 1990), although our approach focused on the moral ecology surrounding 
student question-asking and how question-asking showed up from this perspective. Like other qualitative approaches, this study's findings can be transferred to other contexts (Lincoln \& Guba, 1985), and in that sense, offer applicable insight to other situations and help inform theorizing about this topic.

\section{A Hermeneutic Moral Realist Interpretive Frame}

As we indicated above, the conceptual framework of our investigation was based on hermeneutic moral realism, particularly as offered by Taylor (1985, 1989; see also MacIntyre 1984), but with deeper roots in the hermeneutic-phenomenological work of Heidegger (1962, 1971) and those following in his wake (Dreyfus, 1991, 2014; Guignon, 1983; Hatab, 2000). While this type of investigation has significant overlap with other hermeneuticphenomenological approaches, it is unique in that it specifically seeks to foreground the morallyconfigured, value-laden aspects of phenomena in the contexts of everyday practices. As others have contended, the formulation of novel investigative approaches is often required to produce unique insight into one's subject matter (e.g., Elsbach \& Kramer, 2017; van Manen, 1990). More detailed articulations of what inquiry based on this perspective look like can be found in the writings of some psychologists (Brinkmann, 2011; Stigliano, 1990), including the interpretive frame presented by Yanchar and Slife (2017) which we employed in the design and conduct of this study.

As a framework for inquiry, this hermeneutic-phenomenological perspective begins with practices, conceptualized as more or less cohesive ways of participating in the world, with others, with equipment, and so on, that entail some form of intrinsic good (for more on this concept of practices, see Brinkmann, 2011; MacIntyre, 1984; Stigliano, 1990; Yanchar \& Slife, 2017). From this viewpoint, playing a sport in a given cultural context provides an example of a practice; it involves certain forms of participation and equipment that fit into an overall pattern, performed for certain ends that constitute its intrinsic good (e.g., the enjoyment of playing, excitement of watching, thrill of victory, and so forth). Participating in a practice may also involve extrinsic goods (e.g., monetary payment), but an extrinsic good is not definitive of the practice per se; it is, in this sense, incidental. For example, people can play a sport without any material remuneration, and often do.

Intrinsic goods are integral to practices because they bring with them shape and purpose; they provide a kind of immanent rationale for a practice's existence and activities. But a practice entails more than a cohesive set of activities guided by an intrinsic good. It also entails values or expectations regarding how one ought to go about participating, or what is expected of the good participant - that is, one who pursues the intrinsic good with competence or excellence. For example, the good baseball player is knowledgeable about the game, plays skillfully, follows the rules, is a "good sport," provides a good example to younger players, and so on. In general, from this perspective, it can be said that no engagement in a practice would be possible without these reference points and goods; there would be nothing to orient participants to the practice in correct ways, no sense of what one hopes to accomplish, and no sense of what one should do.

In actual practice, participants will surely act in better or worse ways with regard to these expectations; and how one acts will be evaluated according to how the participant lives up to these goods and reference points in particular situations. Indeed, for this reason these expectations are sometimes referred to as moral "reference points" (Smith, 2002, p. 97; see also Brinkmann, 2011; Yanchar \& Slife, 2017) - they offer guidance regarding how one ought to 
participate in a practice and pursue its intrinsic goods. This is true for any cohesive form of social interaction that entails these goods (e.g., playing games like baseball or checkers, being a teacher, physician, parent, etc.). Thus, the practical and the moral are, from this perspective, inseparable.

From this hermeneutic standpoint, these moral-practical goods and reference points are taken to be as ontologically real as practices themselves. Just as baseball and particular baseball games actually exist in the world, so too do the goods and reference points that enable baseball playing to exist as a practice. In this respect, goods and reference points are not conceptualized as subjective content stored within a putatively private, internal realm of mental life; rather, they exist in the midst of practice, in the real world of engagement and participation, and thus have a kind of moral-practical reality. What we describe here is sometimes referred to as a form of moral realism for this reason (Brinkman, 2011); the goods and reference points that define practices are ontologically-real in this sense and actually exist "out there" in the lived world of participation. For baseball players to excel, for example, they must effectively negotiate the moral configuration of goods and reference points that make participating in any particular game an instance of the practice of baseball.

This understanding of practices extends over vast ranges of human participation. In one way or another, it would seem to apply to much of what people do in the midst of everyday practical involvement. Thus, to understand people in action is to understand them in the midst of practices. And to the extent that this is the case, a satisfactory understanding of vast ranges of human participation will require an account of participation in practices which, in turn, implies understanding cast in terms of moral goods, reference points, and, as we will suggest, the challenges and complexities produced by these moral-practical demands. Inquiry into a given human phenomenon, then, would benefit from consideration of its significance and dynamics within a moral space of practice.

\section{Class Selection and Participants}

This study included eight participants involved in a graduate class on design theory and research in a school of education. This class took a philosophical approach to questions of how human objects and systems are designed, what approaches designers take to their tasks, how design research is conceived, and what kind of meaning is embodied in design activities and goals. It focused on the philosophical background and various design issues in fields such as communications, engineering, computer technology, as well as education. The main course reading was Nelson and Stolterman's (2003) The Design Way. The seminar also included sources such as Simon's (1996) The Sciences of the Artificial, Krippendorff's (2006) The Semantic Turn: A New Foundation for Design, Cross's (2001) Designerly Ways of Knowing, and Lawson and Dorst's (2009) Design Expertise.

Much of the class discussion centered around the proposed and evolving definitions of design in general and problems with different design approaches, particularly the problems of theoretical concepts versus practical applications. The class was assigned readings for each class period and open (unstructured) reflection papers once a week. The goal of the course was to help students survey various approaches to design and synthesize them. The final project was to have each student develop and defend their own formulation of design theory and practice.

This class was chosen for several reasons. First, it was designed by the instructor to be discussion-oriented, with an expectation that students would contribute to class dialogue by 
asking questions; thus, it was likely to provide rich opportunities for studying student questionasking in a formal academic setting. The instructor (pseudonym: Dr. Smith) was an effective discussion leader in the class. He came prepared to class with specific questions to focus and initiate student discussion. He typically directed questions back to group discussion, and encouraged student questions and interaction, often starting class with a request for questions that students had with regard to the reading for that day. At times he let the discussion range freely but would also bring the class back to the text as a basis for exploration. Second, we chose this class because students varied with respect to their familiarity with the subject matter, presumably creating an opportunity to explore the dynamics of question-asking among students with different degrees of knowledge, experience, and confidence.

After we received IRB approval, the instructor and students all agreed to participate and were included in all phases of data collection. Participants, identified by pseudonyms, are described in Table 1.

Table 1

Participant Information

\begin{tabular}{llll}
\hline Name & Gender & Completed Degree & Degree Being Sought \\
\hline Anne & Female & BA & MS \\
Jacky & Female & BA & PhD \\
Harry & Male & PhD & Not seeking a degree \\
Peter & Male & PhD & Not seeking a degree \\
Charles & Male & MS & MS \\
Jim & Male & MS & PhD \\
David & Male & BA & MS \\
Dr. Smith & Male & PhD & Not applicable
\end{tabular}

Professor Smith was a fairly new faculty member in the department, with substantial professional experience in design outside of the university setting.

Harry had already graduated from the department and was taking this class as professional enrichment. He had significant experience with educational theory, but little with design theory. He was primarily interested in developing his own personal learning and teaching model.

Jacky was a doctoral student who had professional experience in curriculum design and concurrently worked part-time at the university as a curriculum design team leader. She had background in instructional design but not underlying theory, and thus took the class out of curiosity about theories of design.

Charles was a master's student, coming into the graduate program after years as a public school teacher and online course designer. He took the design theory course to fulfill part of his master's course requirements at the recommendation of his academic advisor. He came in with experience in curriculum design development but had had little acquaintance with design theory.

David was a master's degree candidate with extensive background in graphic design. He entered the classroom with a question about how his background in graphic design could be integrated and expanded by learning about design theory. He had professional graphic design experience but had done little with either design theory or instructional design.

Peter, a postgraduate with a $\mathrm{PhD}$ in the field, was working as a professional curriculum designer at a different university and sat in on the class electronically. He had conducted research 
in instructional design but had not explored the more general design theories and practices emphasized in the seminar.

Jim was a doctoral candidate with a background focus on language acquisition and extensive teaching experience in foreign languages. His hope was to teach a foreign language at the university level.

Anne was a master's degree candidate who had just received her undergraduate degree the preceding spring. Her long-range goal was teaching supply economics at a business school. She took the seminar because its description sounded interesting to her.

Thus, of the three participants who already had completed PhDs, one was "sitting in" on the course and not seeking a degree (Peter), another was taking it for credit as a work requirement (Harry), while the third was the course instructor. One participant not taking the class for credit attended at a distance electronically (Peter). Regarding participants taking the class for credit, three were master's degree candidates (Anne, Charles, and David) while two were doctoral candidates (Jacky and Jim). Of these participants taking the course for credit, one (Charles) already held a master's degree in another subfield of education.

\section{Data Collection}

Our data sources included class observations, class artifacts, and in-depth, semistructured interviews. Class observations were conducted by one of us (SPG), who attended eight class sessions over a four-week period. Each class session was recorded, transcribed, and analyzed in order to understand ordinary question-asking interactions in class. Question-asking interactions as recorded in class transcripts were primarily used to help guide the semi-structured interviews that we conducted after observations were complete (more on this below). We interviewed each participant three times, with the exception of the course instructor, who we interviewed twice. Each of the interviews lasted approximately an hour.

Interview 1 (conducted by SPG) was used to gain general familiarity with our participants and their typical ways of engaging in class discussions. Interview 2 (also conducted by SPG) was used to explore specific instances of question-asking and ensuing class discussions. These interviews were highly tailored to each participant in light of their involvement in class. Interview 3 (conducted by both authors) was used to more deeply explore issues raised in the first two interviews and obtain participants' impressions of the themes that we had developed at that point. With regard to the course instructor, we used a similar approach, though condensed into two interviews. In interview 1, one of us (SPG) explored his views on student learning and question-asking in general; in interview 2, we together queried into question-asking interchanges from this class, his impressions of our emerging themes, and a few related issues. (For examples of interview questions, see Table 2.)

Table 2

\section{Example Interview Questions}

Interview 1

- "Why are you taking this class?"

- "How does the class fit into the bigger picture of your studies or purposes?",

- "How often do you ask questions?"

- "What kind of questions did you ask in general?"

- "Are your questions like your classmates or different? How so?" 
- "Do the questions you're exploring in class fit with the questions that you need to have answered professionally? Please clarify"

Interview 2

- "Let's look at the video (or listen to the audio) to look at your questions. What were you trying to find out here?"

- "What did you mean when you said ... ?"

- "This answer and that answer seem contradictory. Are they?"

- "What did you think of this questioning interchange?"

\section{Data Analysis}

We analyzed data by way of a hermeneutic moral realist-informed thematic analysis. We prepared for each participant's first interview by becoming sufficiently familiar with artifacts, field notes, class recordings, and class transcripts. While this preliminary review of class context provided an important basis for all interviews, it was especially relevant to interview 2, which focused on question-asking interchanges that had occurred in class. We analyzed interviews independently of one another and later combined our emerging analyses into one overall set of themes (as described below). We followed the same general data analysis pattern: analyze interview 1 before conducting interview 2, and analyze interview 2 before conducting interview 3 (to the point of "initial thematizing;" more on this below). Thus, our interviews 2 and 3 each probed more specifically and deeply into issues raised in earlier interviews. Our analyses of all interviews included the following steps. (What we describe below with respect to analysis is very similar to what has been enumerated in other qualitative reports of this type, e.g., McDonald \& Michela, 2019; Yanchar \& Gong, 2019).

Initial coding. This step involved each of us (separately) reading each interview as it was transcribed, in order to gain a general sense of the whole and begin identifying parts of interviews that were particularly relevant to our research questions. To facilitate the process of identifying phenomena from a hermeneutic moral realist perspective (e.g., goods, reference points, tensions, related forms of participation) we developed a set of a priori codes. We often assigned more than one code to a passage or interchange. These initial, generic codes had to do with issues such as descriptions of practical involvement in class (coded as P), explicit value judgments made by students (coded as V), student self-evaluations (coded as S), instances in which questioning enabled (coded as $\mathrm{E}$ ) or hindered (coded as $\mathrm{H}$ ) a student's ability to do something, and noteworthy observations that did not fit into these codes $(\mathrm{O})$.

Expanded coding. Once we each completed initial coding of a transcript, we (separately) revisited the initial codes (usually after an interim period of one or more days) to check on their appropriateness and made changes as needed. Also during this step, we augmented each initial code with a more detailed "expanded" code. For example, in one transcript one of us supplemented the initial codes "P, V" with the expanded code: "Didn't want to hijack class; it's ok if questions/discussion go in other directions."

Initial thematizing. In this step, we each (separately) began formulating themes by grouping together expanded codes that had similar or related meanings. Through this process we independently created a number of initial themes, each of which was later deleted, revised, or integrated into other themes.

Initial inferring. In this step, we (separately) made initial inferences regarding goods, reference points, and tensions of practice apparent in the data. Some of our initial inferences 
concerned possible reference points associated with "time usage," "sincerity," and being an "engaged contributor." We made approximately the same inference about the primary good of student participation in this class, which was becoming a better designer through expanded theoretical understanding. Finally, we inferred several tensions and balances, the most substantive and significant of which we include below in our findings.

Refined thematizing and inferring. In this step, we (separately) refined our themes and inferences by merging, splitting, adding, deleting, editing, and so on. While engaged in this refining we also sought to identify interrelations among themes, goods, reference points, and tensions in the data by looking for part-part and part-whole connections (e.g., asking "is this tension related to more than one reference point?" "How are these two reference points related?" or "How does this reference point guide toward the broader good of practice?").

Structuring. In this step, we (together) combined our independently developed themes and inferences into a single collection, which we collaboratively refined into a single thematic structure regarding the phenomenon of interest.

\section{Trustworthiness}

To create a trustworthy set of findings (in the sense described by Lincoln \& Guba, 1985) we utilized the following well-known and widely-used credibility standards: reflexive journaling, peer debriefing, persistent observation, data triangulation, and negative case analysis. By following these standards, in conjunction with our hermeneutic moral realist interpretive frame, we sought provide an illuminating, fair, and defensible account of several interrelated aspects of student question-asking as a moral-practical phenomenon in this graduate school context.

\section{Findings}

In what follows, we present four themes (see Table 3 below) regarding student questionasking as a kind of value-laden participation within a classroom moral ecology. These themes are based on our analysis of two forms of participant lived experience: (a) their experience as students in the classroom, asking questions and engaging in classroom discussion, and (b) their experience engaging with us as researchers as we explored classroom question-answer interactions through interviews, often focusing directly on classroom conversations as they were captured in seminar transcripts. The themes we present below became clarified, first, as we (researchers and students together) reflected on participants' classroom experience and discussed the meaning of specific question-asking interchanges, and second, as we (researchers alone) analyzed classroom interchanges and interview data.

As one might expect, while in class students were absorbed in seminar activitieslistening, talking, questioning, answering, debating, and so on, all with a kind of smooth, tacit familiarity that one would expect in this kind of academic setting. During interviews, on the other hand, students were confronted by statements and portions of dialogue from class which invited more conscious reflection on themselves, others, and the seminar experience overall, inviting them to articulate themselves in a more thoughtful—sometimes analytical, sometimes emotional-way. In this respect, interviews allowed participants to explicate, to some extent, the meanings and understandings associated with their tacit classroom involvement, bringing issues out more thematically, and thus often making them seem more explicit than they actually were in the seminar experience itself. This is especially true of the moral reference points that we discuss 
in our findings (see below). While students didn't speak of moral goods and reference points directly in interviews, we as researchers, guided by a hermeneutic moral realist interpretive frame, took account of their classroom lived experience in this light.

The themes we present are all related to complications or disruptions that somehow occurred in ordinary seminar sessions and revealed something about the practice of being a student qua question-asker in this context - for example, issues pertaining to uses of class time, class preparation (in more ways than one), ways of challenging others, or being an engaged learner. These themes collectively provide a glimpse into the moral demands encountered by students in this seminar and, in so doing, offer a perspective on student question-asking not typically seen in this literature.

\section{Table 3}

Thematic Structure of Findings Regarding Student Question-Asking

Theme 1: Contextual Constraints of Class Time in Questioning

Theme 2: Obligation and Risk in Preparedness and Background

Theme 3: The Complexities of Challenging Questions

Theme 4: The Way Personal Questions Mattered

\section{Theme 1: Contextual Constraints of Class Time in Questioning}

Intertwined with student question-asking was a host of practical and moral complexities about how time constraints could be navigated with regard to questioning in class. Implicitly or explicitly, constraints regarding the use of time, and the ways students dealt with those constraints in classroom questioning exchanges, formed a morally-charged context of practice. More specifically, it became clear the time was treated as a kind of scarce resource and needed to be managed carefully. As David said, when he was asked about why he spoke up at certain times, but not others: "I tried to be aware of how long I'm talking" and "I don't want to be the know-it-all or the Hermione Granger sort of person who takes everyone's time."

Like David, other class members seemed well attuned to how uses of class time would matter to other members of the class. Sometimes this was expressed in terms of avoiding waste, as when Anne concisely stated: "I'm afraid of wasting people's time." This concern was also expressed by some participants in terms of appropriate self-awareness. For example, Harry offered the following self-reflection:

I can be a very dominant personality when I want to. And sometimes even when I don't intend to. And part of the idea is that I recognize that there are some people who are just sitting in the class and listening, and I hadn't heard perspectives from them on things, and by me talking, it didn't create the option for them to answer questions or ask questions. And by me shutting up, it created that awkward silence, or it created the opportunity for them to speak and to be able to share what they felt.

Jacky, as she explained her participation in questioning exchanges during the interviews, said that she worried because, "I tend to talk too much," and "I try to not dominate the conversation. But sometimes I'm not very good at that." Peter felt similarly: "I don't overshare, I hope." Charles talked about this issue in terms of something like appropriate balance: "there's times where I feel like I have some value, I can bring to the conversation, and there's other times I think it's good just to listen and hear new perspectives." 
Ultimately, all of the students, in one way or another, were concerned with what might be thought of as an interrogative opportunity cost: only one question (or set of questions) can be asked at a time, and time in class is limited; thus, upon some reflection, students and instructors may always wonder whether a given question was really worth the time it took to be answered and whether other questions might have been more worthwhile for some, if not many, of the students involved.

Time constraints were also connected to how students perceived their place in the seminar. Anne, for example, was the youngest member of the class and a new admit to the program, so jumping into an advanced class on design thinking, backgrounded sometimes by sophisticated discussions of philosophical issues, left her feeling often that she was in over her head. Not only did she refrain from speaking up or answering questions, she deflected questions that were asked of her, often making a joke or demurring to another classmate when the teacher or other students tried to engage her. In her eyes, she was so far behind the others that her questions would be "too basic" for the other students, and it would take too much time to bring her up to speed right there in class. Peter, on the other hand, had already graduated with a PhD from the program and was not taking the class for credit. He would typically decide which of his questions were appropriate to ask in class based on the notion that his non-credit status gave him less legitimate access to class time, and so he only asked questions that he felt added to the discussion at hand. According to Peter, his questions would be problematic if they appropriated or "hijacked" class time for his personal professional goals.

Thus, exploring contextual constraints on time revealed how students viewed what might or might not constitute a worthy question. Some questions were deemed too simple, especially for graduate study, while others seemed idiosyncratic and not relevant to some or most other students. Some questions might be insensitive to others (in substance and not just form), some incomprehensible, some distracting or diversionary from the topic at hand, and some asked at inopportune moments. Across these variations was a kind of concern for everyone's edification, which a given student's question may or may not help achieve. This was a recurring theme among participants, even those who asked questions most frequently and seemed least concerned with allocations of time. From this hermeneutic moral realist perspective, then, the good of education-conceptualized as something like the intellectual growth and development of learners in a particular domain - is obstructed or made less attainable when time is not wisely utilized. To the extent that this is the case, responsible use of time functioned as a kind of moral reference point; it provided implicit moral-practical guidance regarding how students ought to pursue the classroom good when asking questions.

\section{Theme 2: Obligation and Risk in Preparedness and Background}

Participants in this study connected responsible - and thus morally-practically correctclassroom questioning with adequate background and preparation in several interrelated ways. For one, student questions should be informed by a reasonable, if only basic, understanding of the course content, aided by course readings and other assignments. On this issue, students were fairly firm. As Jim stated with regard to any student who would ask questions without being sufficiently prepared: "you should have just done the reading and then you would know the answer to your question, we don't need to answer this question in class, just go back and do the reading."

Through interviews it became clear that students had varying styles of class preparation 
and varying levels of background with regard to the subject matter. A number of the students read the assignments and wrote their reflection papers by the deadline (prior to class) but did not formulate questions for class in advance. If they asked questions during a given class period, it was because something confused or intrigued them in the midst of discussion. Jacky, however, was more deliberate in how she would formulate questions for class. She would start preparing for an upcoming class session a week ahead of time. She would read the course reading assignments first, explore alternative, tangential or related readings, and then reread the assignment again right before class. She took notes from the beginning and began work on writing her reflection paper after her first review of the material. In the time just before class started, she would tighten her reflection paper and note questions she was interested in exploring with the professor and other students. Anne, on the other hand, was more tentative in her approach. Often confused by the readings, she would typically wait for the classroom discussions to aid her interpretations of them, often writing her reflections on topics the class had already covered.

When asked about their class preparation, in conjunction with question asking, participants were quite comfortable using a language of obligation: should or ought. They saw these expectations as an ordinary and inevitable part of being a good student - simply the way things are in an enriching class environment. In this regard, class preparation functioned as another moral reference point: a kind of guiding value in the midst of practice regarding how a good student participates on a regular basis. As reported by participants, however, adequate preparation was important not only for one's own academic success; it was necessary for one to be a meaningful contributor in class and to facilitate a quality educational experience for all. Questions that could be answered by way of adequate preparation, and that prepared students need not ask, were seen as unnecessary and, in the hermeneutic sense we have described here, morally-practically problematic.

The course instructor offered insight into this issue by suggesting that he observed a decrease in the quality of student questions and class discussion toward the end of the term. He described the situation as follows:

I felt that the quality of reading that went into the class preparation went down.

And students even admitted that, they didn't read as much. And so, I think the quality of discussion degraded a little bit maybe the last week of the term, just because the students were less prepared to have good conversations, so they were coming with less questions and they were less able to answer my questions because they weren't as prepared.

Consistent with this moral-practical reference point, and conscious of their standing before the other students and instructor on this matter, participants related that they themselves felt a sense of disquiet when not properly prepared for a class. It was common in interviews for participants to say things like: "If I didn't really put forth an effort, then I probably would sit back and hide and not try and draw attention to myself" [Jim]; "If I haven't engaged with the text very much, then I don't want to take up a lot of time or take time away from people that have done the reading and do know what they're talking about" [Peter]; and "I think there's always a hesitancy when you're not sure you're asking a good question, you didn't want to seem ignorant or that you don't know what's happening" [Charles].

A second sense in which participants expressed concern about adequate preparation for the seminar had to do with their general background in the subject matter and how their in-class questions, as a reflection of that background, would be perceived by other students and the 
instructor. Participants felt that they needed to be already aware of the basic nature of the field, the key thinkers and concepts, and typical ways of thinking, knowing, and doing, even if in a relatively fledgling or intermediate way. Without some background of this sort, student questions would be too basic, perhaps embarrassingly so, and not able to contribute significantly to a graduate-level discussion of ideas and practices. Some participants wondered about their ability to function at this level, as they came from a variety of undergraduate majors or professional fields. David, for instance, had a practical background in graphic design, but not in design theory or education, and thus was skeptical of the adequacy of his background for the seminar, especially during the first weeks of the semester. As he stated:

they always say that there's no stupid questions, but there are questions that make you feel like an idiot. And so, asking that kind of question in a class where people are obviously PhD students, master's students coming into this, and I'm thinking, I'm going to ask a really basic question here that's almost like, you know, how do you use a pencil? And people are just going to say, why is this guy in this class? He's really out of his league here.

In later interviews, David remarked: "That's why I didn't want to ask too much to reveal my ignorance at the beginning." And as a coping strategy, he admitted that he often refrained from asking questions at this early point in the term, relying instead on questions asked by others to clarify course material. David was not the only student concerned with being unprepared, uninformed, and unable to function at the same level as others in the class. Anne, when asked in interviews to explain her reticence in class discussions, shared that she often felt like a "secondclass citizen;" or in her words:

I feel like everyone else has all of this experience with design and with interacting and with being in the practice. And I frankly don't want to be an idiot, and I don't want to hold the class back from ideas, so I feel like really intimidated a lot of times with opening up.

In rendering these self-assessments, participants seemed to be evaluating their questions in light of another moral-practical reference point: they must be academically prepared for a class like this with adequate background; and if they do not, their basic questions should not be asked, as they're not appropriate - they don't lead to enriching discussions and would likely end in a sort of academic embarrassment. In short, these kinds of questions would not be worth whatever benefit they might yield. The risk was too high.

Participants talked about two general ways of handling this issue. One way, according to Harry, was not to be overly self-conscious or "care what other people think." This statement appears to be connected with a primary good of the class itself: edification of learners. If a student lacks knowledge or clarity, she or he should just ask. But this sentiment does not square fully with the lived reality of our participants, who often withheld their questions in the face of conflicting demands - for example, a distinct impression, in the presence of others, that a question was too simplistic and seemed to reveal ignorance.

A second way of dealing with the issue of inadequate background, as described by our participants, was to become familiar with course subject matter through one's own personal study rather than asking questions in class. Perhaps not surprisingly, the obvious resource to use in one's personal study was, for our participants, the internet. The good student should be able to catch up with the rest of class by making use of various websites and databases. Indeed, according to several of our participants, questions that could be answered via an internet search were not, generally speaking, appropriate. When David was asked about how he evaluated some 
of the questions in class, he suggested: "if this was a basic question that I could answer with a Google search, there's no need to put a pin on it for class time. I could go solve that myself." With an adequate background, however, participants would be able to engage more fully in question-asking interchanges and make helpful contributions. And as David's experience suggests (described above), some students were counting on others to make those contributions. Moreover, as suggested by participants, what one finds on the internet may itself be worth asking about in class if it enriches the discussion, broadens the scope of interest, creates connections, and facilitates learning.

But to engage in personal study of course subject matter (especially its rudimentary concepts and underpinnings), instead of asking basic questions in front of other students, was not always a straightforward process of obtaining useful information. As Anne reported, her internet searches sometimes increased rather than reduced her confusion, leading to a sort of diminishing academic returns. Charles noted challenges associated with the sheer volume of information on the internet: "you can kind of do overload. You find yourself looking and looking, and there's so much stuff out there." Without the class community as a resource for clarifying course content and related internet information, students would be unable to assess what they were encountering and equally unable to receive assistance because of their unwillingness to seek more help during class discussions. In this regard, there seemed, at least at times, to be a tension between one's own efforts to master course material and an edifying class experience for all.

It is perhaps for this reason that some participants did not affirm the practice of personal internet study in moments of basic uncertainty; or they agreed that personal internet study might be useful at times (for simple, relatively minor questions), but not as a primary learning resource. For example, some participants suggested that asking basic questions could allow other students to see various perspectives on, or interpretations of, the subject matter; it could clarify confusion that many students might have, but not be willing to ask about due to the anxiety that we have already described. Thus, it was not always clear to participants how to cope with reference points pertaining to background and preparedness. It appears that there were times to ask basic questions and times to refrain. There was no clear, unambiguous rule to follow, but rather a need for judgment, sensitivity, balance, and practical wisdom in context.

Interestingly, it was Dr. Smith who most clearly wondered about students' ability to locate the best online sources and critically assess their content. While he recognized that students could, at times, find correct answers to their questions on the internet, a lack of careful analysis of online information could lead to erroneous understandings. From his perspective, class time itself offered a very appropriate platform for such analysis. Moreover, the instructor was not convinced that basic questions about course content were inappropriate in the first place. He expressed the view that it was often basic questions that would have helped students the most. This remark suggests that, from the instructor's perspective, students may not have been as prepared as they took themselves to be, at least at some points in the course. As he stated: "There were some of those readings that I wish the students would have asked more substantive questions about what was the author trying to say." And a little later in the same interview:

Because I want to make sure that when we're asking those other questions about "what does this mean?", "what is the value of it that we're talking about?" we're asking those questions from an informed place. And based on the way some of those discussions went, I'm not always sure that they were asking those questions from an informed place.

Having said that, however, the instructor also suggested that some basic questions are more helpful than others. Thus, while this moral reference point about question-asking and 
background may seem simple in one sense-good questions will lead to illuminating conversations for most students and not be overly or problematically basic - that simplicity seemed to obscure a deeper complexity directly related to student involvement: It's not always clear what a good question looks like in a given situation and who might benefit from its being answered. This complexity likely follows from a set of reference points that do not fit into a simple, unproblematic picture of good class involvement by student and instructor. The more one's participation seemed to honor one reference point in some way, the more likely it was to de-emphasize another.

\section{Theme 3: The Complexities of Challenging Questions}

We have suggested that class preparation and general background was an enabling condition, though sometimes a hindrance to question-asking for participants in our study. From a hermeneutic standpoint, background is largely tacit and taken for granted in some way. But a student's background and understanding of course readings may be subject to clarification and challenge, which is part of education according to hermeneutic thinkers (e.g., Gadamer, 1989; Slife \& Williams, 1995). Our interviews and observations suggested that questions qua challenges played an important role for students and that being willing to ask these kinds of questions functioned as a moral reference point.

As classroom interactions evolved throughout the term, however, it also became clear that students had different styles of questioning and different approaches to the challenges inherent in their questions. Harry, for example, was comfortable questioning the basic assumptions of the authors whose readings formed the basis of discussion. He had his own strong opinions and would often strike at the core of the assertions made by the experts in the field. He openly challenged (i.e., questioned) the professor at times, and in his personal stories during the interviews he revealed a remarkable sense of ease about what might appear contentious to others. The following excerpt from class, in which Harry questioned how theoretical precepts advanced in the reading for that day were being discussed, was typical for him:

So, he's got this model that's here, and we can see where it fits and it works here, and we never take a step out of that model to see where it doesn't work, and where it breaks down, and the second issue I have kind of relates to education, is he looks to design for the algorithm that accounts for everyone, but it never accounts for everyone. And that's the struggle that it has."

In an interview, Harry told a story of this kind of interaction when he was a graduate student: When I worked on my doctoral program, I worked with a friend... and he and I on some points would adopt a very adversarial position. We would really go at each other, back and forth, arguing our points, like deep down dirty dog arguing. But neither of us took it personally...So, I have had that style, it's a very abrasive and confrontational one...I don't see it as a negative thing... because it makes me stronger, you know. It's kind of like that phrase "you don't always make my life easier, but you do make it better."

Jacky, too, enjoyed vigorous back and forth dialogue about core issues. She relished the task of identifying assumptions and examining them closely. She felt that challenging authority was an inherent part of growing and learning. Over time, however, her style had become even more other-centered than Harry's. In interviews, she confessed that in the past she had 
inadvertently offended professional and academic peers by not appreciating how threatened they might feel when challenged. She had become much more cautious in group settings, she said, and had developed a pattern of approaching fellow students after class in private to check in on their emotional state. Her style had a lot to do with her rationale for limiting her challenging comments and questions. She said that when "challenging became personal" it would be wrong. She seemed to be pointing to a related reference point when she noted that "Honoring and respecting that creating a threatening environment inhibits other people's learning matters to me... . For sure I don't want to hurt people or offend people with the questions I ask."

For example, in one class session Jacky questioned the idea, presented in that day's reading, of design being facilitated through "breathing together," a concept of unified action through a deeply shared vision. This notion was "so Utopian" to her that she felt it could not be taken seriously, which prompted her to ask the question, "Who's ever been in a design relationship like that?" While the class laughed at her cynical question, some found the idea of working in that unified way appealing. One member of the class claimed to have actually experienced it and stated so during the discussion. Although Jacky's experience had mostly involved team members with differing perspectives and agendas, she picked up on the class sentiment and offered a softened view, emphasizing points of agreement. She admitted that this kind of unity could be achieved, "if the members of this design partnership, the service partnership, truly share [a certain] outcome as their goal instead of their personal motive or their personal intention."

In one interview Harry made a similar comment about this kind of sensitivity, suggesting that how he treated other students would make a difference in the appropriateness of the challenge. As he worded it, being "abrasive" and "confrontive" was not in itself wrong, but it became problematic if people took his forceful questioning in the wrong way. He suggested that it was acceptable when the parties involved found it edifying.

With an even greater sensitivity to others, Charles emphasized the importance of kindness when questioning and challenging — what seems to be another reference point to consider. When asked about his pattern of holding back in challenging discussions, he summarized his stance as follows: "If it isn't kind, don't say it." Others in class seemed to share this view, to some degree at least, and at times would rather withdraw from a conversation than create distracting interpersonal tension. For example, during an interview Anne stated that, on one occasion, she refrained from challenging another student on the grounds that it could be taken the wrong way and possibly strain relations in class - a possible result that she saw as unacceptable. As she put it: "rather than cause that uncomfortable confrontation or make him defensive or make him think that I was challenging him to be confrontational, I just didn't ask questions or didn't say anything to him." Her response was informed by earlier classroom interactions, as she had already seen others push back against this student several times (which is another option available to students) and felt that she might initiate a negative pattern of interaction with him if she pushed back also.

Despite differences in how students participated in challenging situations, there was substantial agreement, in general, about the value of challenging others through questioning and confronting. Dr. Smith and most of the students agreed that questions which challenge others are helpful to learning: they open up new perspectives; they explicate what is tacitly assumed; they expand ways of seeing the world; they show limitations in one's thinking; they help learners grow. As we have suggested, for Harry this kind of challenging and being challenged made for better learning. In a similar vein, Jim suggested that helpful questions "challenge ideas and the 
assumptions behind them," and furthermore that if people aren't willing to challenge and be challenged, "they will ask superficial questions." In this sense, Jim suggested that real learning and real depth of thought flow from this kind of questioning. For Jacky also, challenges led to good questioning. While discussing (in an interview) how she felt about several of the challenging interactions in the classroom, she said, "I love being challenged because it makes me question my assumptions." For Jacky, such challenges and questions were a part of learning itself:

My personal learning is enriched through...challenging of ideas and thinking in new ways...I don't want a learning experience that just confirms my preconceived notions. If I'm not changed, if my eyes aren't opened to a different thought or different viewpoints, then I'm not sure how rich my learning is.

\section{Theme 4: The Way Personal Questions Mattered}

An important aspect of questioning which emerged in the seminar we refer to here as the personal question. In using this phrase, we mean a kind of centrally-important question for individual students that informed, to a significant extent, how course material would show up for them - that is, as relevant or irrelevant, interesting or uninteresting, worth asking about or not, and so on. One's personal question would be based on what mattered to her or him in a broad sense, offering a kind of reason (either tacit or explicit) for engaging in class discussions in certain ways and informing what she or he saw as a more or less meaningful question-asking interchange. In this sense, it might be said that a student's personal question offered them $a$ way of being in this class.

For example, theorizing provided by Krippendorff's approach to design was deeply engaging to Peter and Jim, but less so to David and Charles. On occasion, a question or discussion was intensely interesting to everyone. For example, the moral ambiguities inherent in certain designs, such as that of the atom bomb, were engaging on some level to all the members of the class. To be sure, students often asked questions not directly related to their personal question; and a few students seemed to have multiple questions of this sort or, on the other hand, none at all. Nonetheless, our exploration of participants' personal questions revealed layers of meaningful engagement by students in the classroom questioning exchanges - a sense of how the classroom showed up as mattering to them in various ways.

Peter, for example, had been interested in experience-based learning since he took a class on experience design in another department. This previous class had served as a practical counterpart to his theoretical interest in learner agency. However, while he wanted to be true to these major concerns and interests, he also wanted to be professionally credible and accepted by others in the field. Thus, in the current class he wanted to know if his commitment to experiencebased design and learner agency would facilitate his career aspirations. As he noted, "Always as a kind of a background concern of mine was 'what's the viability of this kind of talk [about student experience and agency] in our field?'” Although Peter explicitly articulated his question concerning professional possibilities only once in class during the term, he said that it was a "pretty important question for me to figure out" and "And so, I had that big question about prospects for scholarship all along, but I waited until it kind of emerged from the discussion in the usual material of the course to ask it and to really voice that."

Similarly, through interviews Anne revealed two personal questions that guided her interests in the course, questions which she brought with her into nearly every situation: "why do 
people do what they do?" and "what is happiness?" These two grand questions prompted her interest in becoming a teacher. Anne anticipated a future of teaching business classes at a university, and the extent to which these two questions were addressed in some way provided the basic standard by which she could measure the success of her teaching. But this led to a problem: for her, teaching, had little to do with principles of design and much to do with people's motivations and what makes them happy. She was interested in how teachers touch and are touched by the lives of their individual students. Given this frame of reference, it is easy to see why she often felt bewildered by class discussions. They did not address questions that mattered most to her; or their nature and genuine relevance to education was, for her, obscured by her focus on her two personal questions.

Jim, on the other hand, saw the seminar content and goals as well tailored to his personal ambitions. He wanted to teach second language learning at a university. When asked in the interviews about his purposes and the course purposes, he said, "I felt like they were well aligned." Thus, when conversations and questions seemed to take classroom discussions off into what he thought might be personal tangents, posturing, or aimless opining, Jim became frustrated and withdrew from the discussion, keeping his questions to himself. Jim judged that classroom questions ought to enhance the potential professional possibilities of all the students and that questions which diverted appropriate discussions were an infringement on others' opportunities to learn.

However, personal questions also seemed to serve important moral-practical ends for participants in our study. We observed, through class sessions and interviews, that a personal question could help students stay engaged, lead to useful discussions, bring a sense of connection and cohesiveness to the subject matter, and help provide a meaningful experience. A student who brought a personal question to the course as part of her background was typically an engaged, motivated learner - one who would contribute to the class good, namely, being edified in this area of study. Thus, in our study having a personal question was educationally valuable and functioned as a kind of moral reference point leading to the class good.

As an example, consider a class conversation started by Charles, guided by his personal question regarding how to achieve excellence in design while treating kindness to others as a principal virtue. He made reference to a recent work experience in which he, as project manager, found himself caught between two teammates who had conflicting views on how to proceed on the project at hand. His desire to act in kindness made it difficult for him to side with one of the co-workers and possibly frustrate or alienate the other. As he recounted: "I've gotten halfway through and realized that one person's voice is going to be more important than the other one... and I had to change the entire project to meet that other person." This issue for class consideration, created by Charles' personal question, sparked comments from almost every student about inclusive processes in design work and ways of handling professional relationships. It inspired the students and kept them engaged in the conversation. In this regard, Charles' personal question performed a positive, enabling pedagogical function in the seminar. It pointed out an important issue in design work that, in all likelihood, would not otherwise have come up in class discussions.

However, personal questions could also disrupt the flow of a class session. For example, Anne's lack of background knowledge in the field and preoccupation with her personal questions would at times, lead her to ask questions that did not mesh with what the class was talking about, though they obviously mattered deeply to her. In one case, when covering the work of Herbert Simon, Anne asked about his perspective as a psychologist in a very broad and basic way: "how 
does he [Simon] explain psychology?" Her query set into motion a disjointed exchange among students. One quipped "in ten words or less?", which evoked laughter from others and pointed to the question's lack of fit with the discussion taking place. Finally, Professor Smith intervened by offering a brief, general answer to Anne's question and directed attention back to Simon's view of design. It appeared that Anne's personal questions sometimes worked to conceal from her awareness aspects of course content - because she was, at least at times, more concerned about those questions than topics of concern to others.

Moreover, several participants suggested that students could, on occasion, engage too assertively in class discussions, pressing their agenda and personal queries beyond the point of being instructive. When discussing some question-asking exchanges that seemed to flow out of another student's personal question, David offered the following observation: "it would tend to be drawn out when it seemed to be like a fairly insignificant topic to take so long in discussing it, and so that would just kind of get old, and I felt like it did waste a little bit of class time." From Jim's perspective, time-consuming queries driven by one student's personal question were sometimes frustrating: "there's these ideas that I want to hear from the person that I respect...I want to hear that, but then if something gets in the way of that, I get frustrated by the other person, for instance." Based on our analysis, it appears that personal questions did, at times, motivate this assertiveness among some, though clearly such assertiveness could be motivated for other reasons.

How might students respond to a classmate who, driven by her or his personal question (and its intrinsic meaningfulness), failed to honor a tacit reference point regarding appropriate use of class time? One option, it appears, was to do nothing. And there were moral-practical reasons for doing so. As we described above (in Theme 3), at times Anne would withdraw from discussions rather than push back and possibly strain class relationships. In contrast, Jim described a strategy that might be thought of as an open, yet passive, resistance. As he described it: "I just pull up my phone and I've just looked at Facebook during these comments, and because I just want to give no bodily messages that I am interested in this question. Because I don't think the question is where we should be."

While Jim's strategy may have been effective in some measure, the more typical approach among students was to avoid taking action and, one might surmise, wait for the instructor to handle class management issues. But clearly this is not a failsafe approach, as instructors operate within the same configuration of moral goods and reference points as students (though faced with different expectations), and are thus also caught in complex tensions between individual student needs and the overall good - for example, helping a student feel heard while not allowing him or her to dominate the conversation. Nonetheless, the instructor did report taking some action. As he recounted: "I thought that everyone's contributions in the second half of the term in that regard were probably deeper and I tried to be a little more sensitive to maybe shutting down some things before they would be terribly unproductive."

Whatever might be said about how personal questions mattered and fit within the classroom moral ecology, it was clear that participants faced a constant need to navigate these reference points in dealing with them and, again, that there were no obvious rules to follow in doing so. As stated above, a practical sensitivity to others and the class good in context was required, though not always achieved. 


\section{Discussion}

From the standpoint of hermeneutic moral realism, student questioning as a part of graduate study can be seen as a kind of practice within a practice; and as such, it will be given shape and meaning by moral goods, reference points, and the tensions they produce. It might be said, in this sense, that question-asking exists within, and is made possible by, a network of moral expectations rather than a network of determinant laws and mechanisms (Brinkmann, 2011), as seen in behaviorist and cognitive accounts (Slife \& Williams, 1995). In our study, student question-asking was closely connected with interpersonal and relational concerns as much as knowledge-gathering ones and, indeed, both showed up as aspects of a larger moral enterprise - that of being a good graduate student in this setting. A summary of the primary moral reference points encountered by our participants, as seen in table 4 , provides one broad view of the moral configuration in which participants found themselves.

Table 4

Primary Moral Reference Points in Student Question-Asking

Responsible Use of Class Time

Adequate Preparation for Individual Class Sessions

Sufficient Background for the Overall Class Experience

Engaging in Discussion via Questions

Sensitivity to Context and Others

Challenging Others

Openness to Challenges from Others

Personal Questions

Kindness

As our findings suggest, one's way of dealing with any particular reference point could go too far or not far enough; and many reference points needed to be balanced against others in context. Tensions created by a less-than-optimal balance among reference points seemed omnipresent, often being equally or more influential than instructor expectations or one's desire to learn. And a lack of proper balance sometimes led students to demur. One example of tensions that blocked, or potentially blocked, student engagement concerned the complex interrelation between questions and knowledge - namely, that question-asking presupposes knowledge (qua background) as much as it produces it. In this sense, a student needs to know enough about a topic to ask an appropriate or even intelligible question; and as our participants suggested, not knowing enough, or perceiving oneself as not sufficiently informed, often led to silence. This obviously created an impediment for students who wouldn't ask questions due to a perceived sense of their own deficiencies, but potentially (and actually) for others as well, such as Anne and David, who, due to their own sense of inadequacy, often relied on the questions of others for clarification and understanding. Thus, a tension between needing to know (seeking understanding) and adequate background and preparation for the course was, at least for some, resolved by refraining from queries that might have led to informative discussions for others.

This tension between needing to know and background, and others in the data, reveal a larger, more encompassing tension - that of positioning oneself in terms of the course versus positioning the course in terms of oneself, both by way of question-asking. Clearly participants saw the class as a way to grow professionally and their questions typically reflected their 
interests. For students with a fairly well-developed personal question, class was an instrument by which they could gain important insight and pursue professional development. Student engagement of this sort was clearly apparent in class. In a hermeneutic sense, it might be said that class content and discussions tended to show up in terms of students' personal questions and strivings: as boring or interesting, relevant or irrelevant, and so on. This engagement - treating the course as an instrument in one's own development-was sometimes beneficial to oneself and others, sometimes not (as suggested above).

However, comments from our participants also suggest that they positioned themselves in terms of the moral-practical configurations of the class, as in the obvious case of refraining from asking questions in light of the moral-practical expectation to use time responsibly, or perhaps due to fear of embarrassment. One could not participate in this class, it seems, without encountering and somehow coping with the goods and reference points of graduate student practice in this setting. Indeed, as we suggested above, it is this moral configuration that rendered student question-asking a meaningful practice in the first place. In our study, it is what gave question-asking purpose and form (i.e., with regard to what good students do, how they do it, and so on). For example, good students pursued edification, but in ways that did not obstruct the learning of others. If one's questions seemed not to fit the context in some way, then those questions were asked at risk of disrupting class, creating tensions among students, and possibly impeding edification. Overall, our analysis suggests that here was no escape from a need for balance in context - perhaps some kind of student-oriented phronesis - if one sought to pursue the class good.

Importantly, we acknowledge that the setting of our study was somewhat unique within the world of education. Graduate students are typically motivated learners and graduate classes are, it may be assumed, more discussion-centered than classes at other levels. The degree to which student questions play a role in class proceedings surely varies across contexts, but the depth and complexity of student questions are likely to be greater in graduate study than at most other levels. Thus, the findings of this study may transfer fairly well to some settings (e.g., other graduate courses, some undergraduate courses) and not so well to others (elementary or middle school classes). However, as is often the case in studies of this type, the extent to which these findings may be insightful or applicable remains to be determined by the consumer of the research (Lincoln \& Guba, 1985). And from these methodological observations, it follows that further inquiry into student question-asking at other levels of academics, such as high school and college, or in other class subjects, such as science and humanities, would add insight into the nature of student question-asking as a central aspect of formal learning experiences.

Moreover, in future investigations the motives and intentions of students could be taken into account more directly, with specific attention paid to issues of intrinsic versus extrinsic motivation and how those motivations may lead to subtle, or not so subtle, differences in how students ask questions or how they perceive the questions of others. In the present study, students were often motivated by an interest in instructional design per se and seemed not to be overly concerned with extrinsic matters such as course grade. But for many, their interest was also professional, in the sense of learning in order to be credentialed so they could attain the professional position or status they desired. It is not always easy to discern where intrinsic motivations end and extrinsic motivations begin when the subject matter concerns people's professional aspirations, as interests or commitments with regard to the work per se often merge, or possibly conflict, with practical matters such as professional survival or promotion (e.g., one's desire to design excellent educational experiences can be synergistic with, or oppose, doing what 
is required for professional advancement). Continued research could explore student question asking from this perspective.

Another limitation of this study concerns our focus on student question asking in the classroom. Of course, student questions were situated within a broader educational context that transcended and situated any particular moment in a given class session. For example, a formal itinerary of participation in which student questions could be asked - including course readings scheduled in a certain order, reflection paper assignments, final project, guided conversations, and so forth - was arranged by the course instructor. And the course itself was situated within a specific graduate program that offered a disciplinary context in which students were able to study and learn about educational practices in certain ways. This is all to say that how students asked questions was, in all likelihood, a function of more than specific discussion topics and curiosities at specific moments in the seminar. A larger educational structure made certain kinds of questions possible, in a sense, and that larger structure could be explored what regard to the overall setting it created for student practices, including the moral goods and reference points that students navigated (either tacitly or explicitly). Thus, it must be acknowledged, when interpreting these findings, that this broader educational context was not explicitly addressed in interviews and data analysis. One obvious way forward, in this regard, would be to explore how instructors fit into the moral contexts of classes, especially with regard to the kinds of questions they ask and how they may invite students to contribute in certain ways. Another step would be to explore more carefully how student experiences in other classes - in the past, with other students and instructors - may provide a context for how students ask questions in a current class.

\section{Conclusion}

A hermeneutic moral realist interpretive frame casts question-asking in a unique light and, in our study, enabled this educational activity to be seen as more nuanced and complex than what might be thought of as a purely cognitive, knowledge-acquiring exercise. From this perspective, how students asked questions in this graduate seminar not only constituted a way of being in the classroom, but a moral way of being in the hermeneutic sense that we have described. More specifically, how students asked questions functioned as a kind of commentary on course subject matter and the goods and reference points that they encountered in the midst of everyday class involvement. Moreover, moral tensions in class required deft balancing, in implicit or explicit ways, as participants sought to make the most of class experiences. How participants balanced those tensions was, again, a kind of commentary on the course and the moral configurations that situated their learning activities. In sum, this study-in conjunction with some others (Gong \& Yanchar, 2019; McDonald \& Michela, 2019; Yanchar \& Gong, 2019) — suggests that inquiry of this type can expand the range methodological resources available to researchers and offer novel (i.e., intrinsically moral-practical) ways of interpreting human action in context.

\section{References}

Addison, R. B. (1992). Grounded hermeneutic research. In B. F. Crabtree \& W. L. Miller (Eds.), Doing qualitative research (pp. 110-125). Sage. 
Belnap, N. D., \& Steel, T. B. (1977). The logic of questions and answers. Yale University Press.

Bingham, C. (2005). The hermeneutics of educational questioning. Educational Philosophy and Theory, 37(4), 553-565. http://doi:10.1111/j.1469-5812.2005.00140.x

Brinkmann, S. (2004). The topography of moral ecology. Theory \& Psychology, 14(1), $57-80$.

Brinkmann, S. (2011). Psychology as a moral science: Perspectives on normativity. Springer.

Chin, C., \& Osborne, J. (2008). Students' questions: A potential resource for teaching and learning science. Studies in Science Education, 44(1), 1-39.

Cross, N. (2001). Designerly ways of knowing: Design discipline versus design science. Design Issues, 17(3), 49-55.

Davey, B., \& McBride, S. (1986). Effects of question-generation training on reading comprehension. Journal of Educational Psychology, 78(4), 256-262.

Dreher, M. J., \& Brown, R. F. (1993). Planning prompts and indexed terms in textbook search tasks. Journal of Educational Psychology, 85(4), 662-669.

Dreyfus, H. L. (1992). What computers still can't do: A critique of artificial reason. MIT Press.

Dreyfus, H. L. (2014). Skillful coping. Essays on the phenomenology of everyday perception and action. Oxford University Press.

Elsbach, K. D., \& Kramer, R. M. (Eds.) (2016). Handbook of qualitative organizational research: Innovative pathways and methods. Routledge.

Flammer, A., Kaiser, H., \& Mueller-Bouquet, P. (1981). Predicting what questions people ask. Psychological Research, 43(4), 421-429.

Gadamer, H. G. (1989). Truth and method ( $2^{\text {nd }}$ rev. ed.). Continuum.

Gong, S. P. (2018). The moral realism of student question-asking in classroom practice. (Doctoral Dissertation). Retrieved from scholarsarchive.byu.edu.

Gong, S. P., \& Yanchar, S. C. (2019). Question asking and the common good: A hermeneutic investigation of student questioning in moral configurations of classroom practice. Qualitative Research in Education, 8(3), 248-275.

Guignon, C. B. (1983). Heidegger and the problem of knowledge. Hackett Publishing Co.

Guignon, C. B. (2002). Ontological presuppositions of the determinism-free will debate. In H. 
Atmanspacher \& R. Bishop (Eds.), Between chance and choice: Interdisciplinary perspectives on determinism (pp. 321-337). Imprint Academic.

Harper, K. A., Etkina, E., \& Lin, Y. (2003). Encouraging and analyzing student questions in a large physics course: Meaningful patterns for instructors. Journal of Research in Science Teaching, 40(8), 776-91.

Hatab, L. (2000). Ethics and finitude: Heideggerian contributions to moral philosophy. Rowman \& Littlefield.

Heidegger, M. (1962). Being and time. Harper \& Row. (original work published in 1927)

Heidegger, M. (1971). Poetry, language, thought. Harper Collins.

King, A. (1989). Effects of self-questioning training on college students' comprehension of lectures. Contemporary Educational Psychology, 14(4), 366-381.

King, A. (1994). Autonomy and question asking: The role of personal control in guided studentgenerated questioning. Learning and Individual Differences, 6(2), 163-185.

Koralus, P., \& Mascarenhas, S. (2013). The erotetic theory of reasoning: Bridges between formal semantics and the psychology of deductive inference. Philosophical Perspectives, 27(1), $312-365$

Krippendorff, K. (2006). The semantic turn: A new foundation for design. CRC.

Lawson, B., \& Dorst, K. (2009). Design expertise. Elsevier Ltd.

Lincoln, Y. S., \& Guba, E. G. (1985). Naturalistic inquiry (pp. 289-331). Sage Publications.

MacIntyre, A. (1984). After virtue (2nd ed.). Notre Dame University Press.

Martin, J., Sugarman, J., \& Thompson, J. (2003). Psychology and the question of agency. SUNY Press.

McDonald, J. K., \& Michela, E. (2019). The design critique and the moral goods of studio pedagogy. Design Studies, 62 (c), 1-35.

Mosher, F. A., \& Hornsby, J. R. (1968). On asking questions. In J. S. Bruner, R. R. Olver, \& P. M. Greenfield (Eds.), Studies in cognitive growth (pp. 86-102). Wiley.

Nelson, H. G., \& Stolterman, E. (2003). The design way: Intentional change in an unpredictable world: Foundations and fundamentals of design competence. MIT Press.

Nelson-LeGall, S., \& Glor-Scheib, S. (1985). Help seeking in elementary classrooms: An observational study. Contemporary Educational Psychology, 10(1), 58-71. 
http://doi:10.1016/0361-476X(85)90006-2

Newman, R. S. (1991). Goals and self-regulated learning: What motivates children to seek academic help? In M. L. Maehr \& P. R. Pintrich (Eds.), Advances in motivation and achievement: Goals and self-regulatory processes (Vol. 7, pp. 151-183). JAI Press.

Otero, J., \& Graesser, A. C. (2001). PREG: Elements of a Model of Question Asking. Cognition and Instruction, 19(2), 143-175.

Pedrosa de Jesus, M. H., Almeida, P., \& Watts, M. (2004). Questioning styles and students' learning: Four case studies. Educational Psychology, 24(4), 531-548. http://doi:10.1080/0144341042000228889

Prior, M., \& Prior, A. (1955). Erotetic logic. Philosophical Review, 64(1), 43-59.

Robertson, S. P., \& Swartz, M. (1988). Why do we ask ourselves questions? Questioning Exchange, 2(2), 47-51.

Rop, C. J. (2003). Spontaneous inquiry questions in high school chemistry classrooms: Perceptions of a group of motivated learners. International Journal of Science Education, 25(1), 13-33.

Schraagen, J. M. (1993). How experts solve a novel problem in experimental design. Cognitive Science, 17(2), 285-309. http://doi:10.1207/s15516709cog1702_4

Siegler, R. S. (1977). The twenty questions game as a form of problem solving. Child Development, 48(2), 395-403.

Simon, H. A. (1996). The sciences of the artificial (3rd ed.). MIT Press.

Singer, H., \& Donlan, D. (1982). Active comprehension: Problem-solving schema with question generation for comprehension of complex short stories. Reading Research Quarterly, 17(2), 166-186.

Slife, B. D., \& Williams, R. N. (1995). What's behind the research? Discovering hidden assumptions in the behavioral sciences. Sage Publications.

Smith, N. H. (2002). Charles Taylor: Meaning, morals, and modernity. Polity Press:

Spackman, J. S., \& Yanchar, S. C. (2014). Embodied cognition, representationalism, and mechanism: A review and analysis. Journal for the Theory of Social Behavior, 44(1), 46-79.

Stigliano, A. (1990). The moral basis of human science. Saybrook Review, 8(1), 73-104.

Suchman, L. A. (1987). Plans and situated actions: The problem of human-machine 
communication. Cambridge University Press.

Taylor, C. (1985). Human agency and language: Philosophical papers (vol. 1). Cambridge University Press.

Taylor, C. (1989). Sources of the self: The making of the modern identity. Harvard University Press.

Tsui, A. (1992). A functional description of questions. In M. Coulthard (Ed.), Advances in spoken discourse analysis (pp. 89-110). Routledge.

Van der Meij, H. (1990). Question asking: To know that you do not know is not enough. Journal of Educational Psychology, 82(3), 505-512.

van Manen, M. (1990). Researching lived experience. SUNY Press.

Volkman, M. J., \& Zgagacz, M. (2004). Learning to teach physics through inquiry: The lived experience of a graduate teaching assistant. Journal of Research in Science Teaching, $41(6), 584-602$.

Wheeler, M. (2005). Reconstructing the cognitive world. MIT Press.

Wong, B. Y. L. (1985). Self-questioning instructional research: A review. Review of Educational Research, 55(2), 227-268.

Yanchar, S. C. (2011). Participational agency. Review of General Psychology, 15(3), 277287.

Yanchar, S. C., \& Gong, S. P. (2019). Inquiry into moral configurations. In Slife, B. D., \& Yanchar, S. C. (Eds.). Hermeneutic moral realism: Theory and Practice. Routledge.

Yanchar, S. C., Slife, B. D., \& Warne, R. T. (2008). Critical thinking as disciplinary practice. Review of General Psychology, 12(3), 265-281.

Yanchar, S. C., \& Slife, B. D. (2017). Theorizing inquiry in the moral space of practice. Qualitative Research in Psychology, 14(2), 146-170.

Yanchar, S. C., Spackman, J. S., \& Faulconer, J. E. (2013). Learning as embodied familiarization. Journal of Theoretical and Philosophical Psychology, 33(4), 216-232.

Yuille, J. C. (1986). The futility of a purely experimental psychology of cognition: Imagery as a case study. In D. Marks (Ed.), Theories of image formation (pp. 197-224). Brandon House. 